\title{
Fundamental Indexes As Proxies For Mean-Variance Efficient Portfolios
}

\author{
Kathleen Hodnett, PhD, University of the Western Cape, South Africa \\ Gearé Botes, University of the Western Cape, South Africa \\ Khumbudzo Daswa, University of the Western Cape, South Africa \\ Kimberly Davids, University of the Western Cape, South Africa \\ Emmanuel Che Fongwa, University of the Western Cape, South Africa \\ Candice Fortuin, University of the Western Cape, South Africa
}

\begin{abstract}
Mean-variance efficiency was first explained by Markowitz (1952) who derived an efficient frontier comprised of portfolios with the highest expected returns for a given level of risk borne by the investor. The assumed mean-variance efficiency of the market portfolio along with the fact that it is capitalization-weighted underlies the rationale for market indexes being constructed by market capitalization weights (Mar, Bird, Casavecchia and Yeung, 2009). The pioneers of the fundamental index approach to investing, Arnott, Hsu and Moore (2005), however differ, and argue that market capitalization-weighted indexes are not mean-variance efficient due to their price-sensitivity, which leads to the overweighting of overvalued stocks and the underweighting of undervalued stocks, creating a return drag. The authors constructed an index weighted by fundamental determinants of firm value such as earnings, book value and revenue, proving that their fundamentally weighted index causes the return drag inherent in capitalization-weighted indexes to disappear. The aim of this paper is to discuss the evidence for and the arguments against fundamentally-weighted indexes as proxies for mean-variance efficient portfolios. We conclude that since the market cap-weighted index is only mean-variance efficient given the efficiency of the market, whilst the fundamental index incurs higher turnover, and may contain a value bias, its resistance to investor overreaction makes it a more valid mean-variance efficient proxy in an inefficient market.
\end{abstract}

Keywords: Fundamental Indexation; Mean-Variance Efficient Portfolio; Mean-Variance Efficiency, Stock Market Indexes

\section{INTRODUCTION}

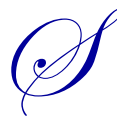

tock market indexes form an integral part of the financial world. Investors monitor these indexes for decision making with respect to their portfolios, using them as benchmarks; whether they are trying to beat the market or simply match it. It should be noted however, that not all indexes are constructed in the same way and that an index can be considered as mean-variance efficient if the maximum return is yielded for a given amount of risk borne. While the market capitalization weighting index is purported to do this, alternative indexes have garnered enough interest to prove otherwise. This paper will discuss the evidence for and the arguments against fundamentally-weighted price-insensitive indexes as proxies for mean-variance efficient portfolios. This will be done firstly; by contrasting price-sensitive market capitalization weighted indexes with fundamentally weighted indexes with the aim of determining which market proxy can be considered more meanvariance efficient. Secondly; the paper will discuss and present empirical evidence for fundamentally-weighted indexes and lastly; the arguments against fundamental indexes as mean-variance efficient portfolio proxies will be presented. Driven by the philosophy that the market capitalization weighted index contains possible inefficiencies and that investor overreaction disturbs fair values, it is concluded that the fundamental index is more mean-variance efficient than the market-capitalization index. 


\section{MEAN-VARIANCE EFFICIENT PORTFOLIO PROXIES}

Mean-variance efficiency was first explained by Markowitz (1952) who derived an efficient frontier made up of portfolios yielding the highest expected return for a given level of risk. This model of mean variance efficiency assumes that all investors are risk-averse and select portfolios that maximize return and minimize risk. The extent to which a risk-averse investor decides to take on more or less risk is dependent on that investor's attitude towards risk. Tobin (1958) put forward the Separation Theorem that divides the investment process into two separate steps taken by the investor. The first step entails finding the efficient portfolio of risky assets. This is based on extrinsic factors such as computing mean, variance and covariance of returns. The second step entails combining the efficient portfolio with a risk-free asset. This is based on intrinsic factors such as the investor's degree of riskaversion. Markowitz (1952)'s Modern Portfolio Theory (MPT), together with Tobin (1958)'s Separation Theorem formed the basis for the risk-return relationship (where total risk is measured by variance of returns) depicted in the construction of the capital market line (CML). The capital asset pricing model (CAPM) later pioneered by Sharpe (1964), Lintner (1965) and Mossin (1966) assumes that all systematic risk factors are captured by market movements, and as a result, market risk (and not total risk as in the case of the CML) is the only relevant risk that investors require compensation for. The market portfolio, the point of tangency between the CML and Markowitz's efficient frontier; and the SML and Markowitz's efficient frontier, is termed a "mean-variance efficient portfolio".

Market capitalization-weighted indexes were considered suitable proxies for the market portfolio. The mean- variance efficiency of market capitalization weighted indexes was justified by the assumption of the efficient market hypothesis which considered prices to be an efficient mechanism revealing a firms intrinsic value. However, given the overreaction of investors to recent information, markets could no longer be considered efficient (Hsieh, Hodnett and Van Rensburg, 2012). The observed inefficiency of capital markets arouses the need for priceinsensitive measures of firm value that are immune to investor overreaction to proxy for more mean-variance efficient portfolios.

\section{Market-Capitalization Index}

The market capitalization weighted index is the most common approach in creating an index (Siegel, 2006) and is calculated by dividing the stock's current market capitalization (number of shares multiplied by the current share price) by the sum of market capitalizations in the index. Weights are calculated as follows:

$W_{i}(x)=\frac{N_{i}(x) P_{i}(x)}{\sum_{j=1}^{n} N_{j}(x) P_{j}(x)}$

where $N_{i}(x)$ represents the number of shares outstanding for the $i$-th stock and $P_{i}(x)$ represents the price of the $i$-th stock. For example, if the Russell 1000, a market capitalization weighted index, had a total market cap of 100 trillion US dollars and the market capitalization for IBM were 25 billion US dollars, IBM would constitute $0.025 \%$ of the index value. Hsu (2006) appropriates the popularity of market capitalization weighted indexes to the indexes benefits which include: no management costs (as it as a passive strategy); minimal rebalancing costs (due to the automatic stock rebalancing) and reduced transaction costs, among others. There is also evidence that the market capitalization weighted index has outperformed some actively managed portfolios (Siegel, 2006). However, it is not without its flaws. The market capitalization weighted index's performance is dependent on the efficiency of the market. If the market is efficient, as per the efficient market hypothesis, then market prices fully reflect all available information (Fama, 1970), and the market capitalization weighted index will offer the best risk-adjusted return (Siegel, 2006). However, when markets are inefficient, the market capitalization-weighted index overweights overvalued stocks and underweights undervalued stocks (Stotz, Wanzenried.\& Döhnert, 2010). Thus, while the market capitalization weighted index is simple to compute and widely used, it is based on underlying theory that does not hold in reality.

\section{The Fundamental Index}

The fundamental index was created by investment management firm, Research Affiliates, with the belief that "investors can do better than cap-weighted market indexes" (Arnott, Hsu, \& Moore, 2005). It is constructed 
using fundamental measures, otherwise known as "Main Street measures" of firm value such as gross revenue, equity, gross dividends, cash flow and total employment (Arnott, Hsu, \& Moore, 2005). Weights are constructed as follows:

$W_{i, t}=\frac{F_{i, t}}{\sum_{j=1}^{N} F_{j, t}}$

where $F_{i, t}$ is the fundamental measure and $\mathrm{N}$ is the number of stocks in the portfolio being considered. The creators of fundamental indexation empirically prove that over a period of 43 years, 1962-2004, fundamental indexes outperform traditional market capitalization weighted indexes on a risk-adjusted basis. The authors attribute the outperformance to the elimination of the return drag inherent in price-sensitive market capitalization indexes (which overweight overvalued stocks and underweight undervalued stocks). The outperformance of the fundamental index relative to the market capitalization index, underlie the rationale for fundamentally weighted indexes as a proxy for a more mean-variance efficient portfolio.

\section{EVIDENCE FOR FUNDAMENTAL INDEXATION AS A MEAN-VARIANCE EFFICIENT PROXY}

Proponents of MPT hold that the market portfolio, which is cap-weighted, is mean-variance efficient and that in an efficient capital market, the prices of securities reflect their intrinsic worth. However, due to the noisiness of prices under real economic conditions, which violates the mean variance efficiency assumption of MPT, alternative price-insensitive weighting models such as the fundamental index have been created to overcome or take advantage of the cap-weighted weaknesses. The primary reasons for the use of a fundamental index as an alternative to the popular cap-weighted index lies in the fact that capitalization is a very volatile way to measure the true value of a firm; as well as the overweighting of overvalued stocks and underweighting of undervalued stocks in the construction of cap-weighted indexes (Arnott, Hsu and Moore, 2005). Despite the on-going criticism of the logical and mathematical consistency of the fundamental weighted index, there exists evidence for its superiority to the capweighted index:

\section{Market-Cap Benefits Retained}

The market capitalization weighted index has become the standard method of indexing due to an array of benefits it offers. For an alternative index to be considered as better, it should retain all, or most, of these benefits and outperform the current index in those aspects. The fundamental index attempts to do exactly this, Arnott et al. (2005) identify four benefits that any alternative index should seek to retain:

- Turnover is lower than an active strategy. Since the market capitalization weighted index is a passive strategy, and the portfolio rebalances itself when prices change, turnover is considerably less than that of an active management strategy.

- $\quad$ Easier access granted to the broad equity market. The market capitalization weighted index gives larger weights to the largest companies.

- Transactions costs are reduced. Due to the high correlation of market capitalization with liquidity, the portfolio invests more in stocks that trade more heavily.

- $\quad$ Market cap weighted indexes place greater emphasis on stocks with greater investment capacity

Arnott et al. (2005) further found that the fundamental index is able to retain the benefits of liquidity and investment capacity, however, due to the method of rebalancing turnover is considerably larger with the fundamental index.

\section{Better Measure Of Firm Size}

One of the lofty claims of the fundamental-weighted index is that it represents a better measure of the weights of the stocks included in the index. Share prices are subject to market influences and investor overreaction, resulting in weights that do not truly reflect the fair price of the stock. Fundamental metrics are independent of price measures and other market and investor influences, making them a better reflection of size and performance of large established firms in the capital market (Hsieh, Hodnett \& Rensburg, 2012). 


\section{Market Price Noise Resistance}

The noisy market hypothesis states that stock prices are vulnerable to temporary shocks (or noise) which, consequently, distorts a stock's fair value (Siegel, 2006). Additionally, if investors overreact to new information, as per the overreaction hypothesis (De Bondt and Thaler, 1985), this distortion may be accentuated by irrational behaviour. As mentioned previously, market capitalization indexes only offer the best risk-adjusted return if markets are efficient, if however markets are inefficient; noise within the market is quite significant. Hsu (2004) found that where noise exists, there is a return drag in the market capitalization weighted index which is not found within an index based on fundamentals due to fundamentals not being affected by noise within the market. Thus, as a result of "Main Street measures" being the basis of the fundamental index's construction, the index is resistant to noise within the market, strengthening the mean-variance efficiency of the fundamental index.

\section{Greater Return for Lower Risk}

There is existing evidence that fundamental indexes generate significantly better returns than the market capitalization-weighted index. This result has shown to be prevalent in index comparisons across the globe. In the United States, Arnott et al. (2005) found that their fundamental index outperformed the S\&P 500 (a market cap weighted index) over a 43 year period from 1962 to 2004. When constructing a fundamental index for the respective countries, similar results were found for the ASX200 and ASX300 in Australia (Mar, Bird, Casavecchia, and Yeung, 2009) and DJ Stoxx 600 in Switzerland (Stotz et al. 2010).

Figure 1 tracks the 5-year returns performance of the FTSE/JSE RAFI 40 and the FTSE/JSE Top 40 in South Africa.

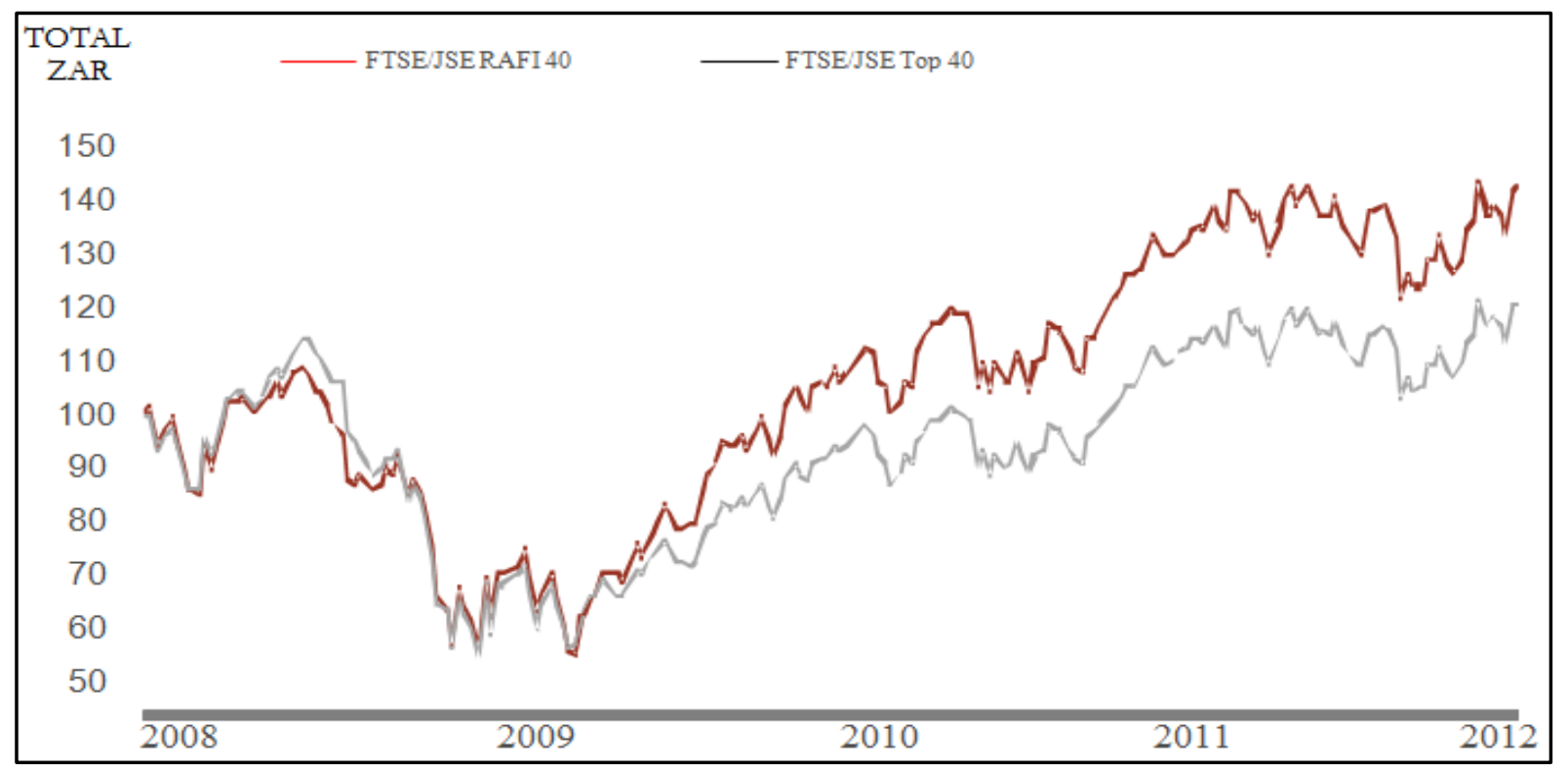

Source: http://www.ftse.com/Indices/FTSE_JSE_Africa_Index_Series/Downloads/FJRI.pdf

Figure 1: FTSE/JSE RAFI 40 versus FTSE/JSE Top 40

Compared to the FTSE/JSE Top 40 (which is cap-weighted), the FTSE/JSE RAFI 40 has steadily outperformed the FTSE/JSE Top 40 since 2008, with a 9.2\% annualized return over the 5 year period compared to the FTSE/JSE Top 40's 7.1\%. In addition to the higher return, FTSE/JSE RAFI 40 was less risky, with $18.1 \%$ volatility compared to the FTSE/JSE Top 40's 19.8\% (FTSE, 2012). In a much broader study, Walkshäusl and Lobe (2009) found that of the 50 countries in their study, global fundamental indexes and 44 of the 50 country-specific fundamental indexes created higher returns. In each of the above cases, the fundamental index earns a higher risk adjusted return, for a lower level of risk. This supports motivation for the fundamental index as a mean-variance efficient proxy of the market. 
Although designed for simplicity and appeal and therefore a priori assumed not to be an efficient way of tapping into the value premium of value stocks (Blitz and Swinkels, 2008), fundamental indexation has proven to generate much higher returns than cap-weighted indexes, with no added risks. Research on this issue by Arnott $e t$ al. (2005) and Hsieh et al. (2012) have confirmed this position. Arnott et al. (2005) constructed a fundamental index with size measures including, book value, and trailing five year values of cash flow, dividends, sales, and total employment. Dividends were however excluded from this fundamental index for independent examination. A composite index was also constructed from equal weightings of the four measures of size used in the fundamental index. A reference cap-weighted index was constructed and the S\&P 500 was employed for performance comparison purposes (the market proxy). The results over the 43 year examination period, tabulated in Table 1 , demonstrate a marked outperformance of both the S\&P 500 and reference cap-weighted indexes by the fundamental index by an average of $1.97 \%$ and $2.15 \%$ excess returns respectively; the sales index being the highest performing of the indexes with a superior return of $2.56 \%$. Even after turnover (trading cost) is adjusted for, which is assumed a $2 \%$ round-trip transaction cost, the fundamental index stays well ahead of the reference index by at least $2 \%$ points.

Table 1: Return Characteristics Of Alternative Indexing Metrics, 1962-2004

\begin{tabular}{|c|c|c|c|c|c|c|c|c|}
\hline $\begin{array}{l}\text { Portfolio/ } \\
\text { Index }\end{array}$ & $\begin{array}{c}\text { Ending } \\
\text { Value of } \$ 1\end{array}$ & $\begin{array}{c}\text { Geometric } \\
\text { Return }\end{array}$ & Volatility & $\begin{array}{c}\text { Sharpe } \\
\text { Ratio }\end{array}$ & $\begin{array}{c}\text { Excess Return } \\
\text { vs. Reference }\end{array}$ & $\begin{array}{c}\text { Tracking Error } \\
\text { vs. Reference }\end{array}$ & $\begin{array}{c}\text { Information } \\
\text { Ratio }\end{array}$ & $\begin{array}{l}t \text {-Statistic for } \\
\text { Excess Return }\end{array}$ \\
\hline S\&P 500 & $\$ 73.98$ & $10.53 \%$ & $15.1 \%$ & 0.315 & $0.18 \mathrm{pps}$ & $1.52 \%$ & 0.12 & 0.76 \\
\hline Reference & 68.95 & 10.35 & 15.2 & 0.301 & - & - & - & - \\
\hline Book & 136.22 & 12.11 & 14.9 & 0.426 & 1.76 & 3.54 & 0.50 & 3.22 \\
\hline Income & 165.21 & 12.61 & 14.9 & 0.459 & 2.26 & 3.94 & 0.57 & 3.72 \\
\hline Revenue & 182.05 & 12.87 & 15.9 & 0.448 & 2.52 & 5.03 & 0.50 & 3.25 \\
\hline Sales & 184.95 & 12.91 & 15.8 & 0.452 & 2.56 & 4.93 & 0.52 & 3.36 \\
\hline Dividends & 131.37 & 12.01 & 13.6 & 0.458 & 1.66 & 5.33 & 0.31 & 2.02 \\
\hline Employment & 156.83 & 12.48 & 15.9 & 0.423 & 2.13 & 4.64 & 0.46 & 2.98 \\
\hline Composite & 156.54 & 12.47 & 14.7 & 0.455 & 2.12 & 4.21 & 0.50 & 3.26 \\
\hline $\begin{array}{l}\text { Average } \\
\text { (ex Composite) }\end{array}$ & $\$ 159.44$ & $12.50 \%$ & $15.2 \%$ & 0.444 & $2.15 \mathrm{pps}$ & $4.57 \%$ & 0.47 & 3.09 \\
\hline
\end{tabular}

Source: Arnott, Hsu And Moore (2005: 86)

Similar research performed by Hsieh et al. (2012) produced quite comparable results. The research data spanned the period from January 1991 to December 2008, subdivided into two sub-periods denoting periods of expansion and contraction of the equity market. The authors utilized the Morgan Stanley Capital International (MSCI) as the market proxy, as opposed to the S\&P 500 employed by Arnott et al. (2005). To ensure representation of the stocks in major sectors of the global equity market, the Dow Jones (DJ) Sector Titans Composite index is employed as the database. The authors also constructed cap-weighted and fundamental weighted indexes of 200, 100,50 , and 30 stocks based on capitalization and trailing five year values of fundamental attributes, respectively, to investigate the effect of portfolio concentration. The portfolios are rebalanced on a four-month basis. Performance is presented both on a cumulative and risk-adjusted basis, with measures such as the Sharpe ratio, the Treynor ratio and Jensen's alpha employed to adjust for risk. All the fundamental weighted indexes outperformed the capweighted indexes throughout the examination period but earned comparable returns with the MSCI index during the expansionary period 1991-1999, with considerably less losses sustained during the contractionary period. Also, the fundamental indexes generate volatilities which are slightly higher than the MSCI index. Not only do the fundamental indexes generate higher average monthly portfolio and risk-adjusted returns, they also have lower than average beta coefficients. The cap-weighted indexes, however, display higher than average betas during the expansionary phase and slightly lower than average betas during the contractionary phase. Results ate depicted in Table 2 and Table 3. 
Table 2: Basic Performance Statistics Of Size Indexes

\begin{tabular}{|c|c|c|c|c|c|c|c|c|c|}
\hline Period & $\begin{array}{l}\text { (1) MSCI } \\
\text { World }\end{array}$ & $\begin{array}{c}\text { (2) CAP } \\
200\end{array}$ & $\begin{array}{c}\text { (3) CAP } \\
100\end{array}$ & $\begin{array}{c}\text { (4) CAP } \\
50\end{array}$ & $\begin{array}{c}\text { (5) CAP } \\
30\end{array}$ & $\begin{array}{l}\text { (6) FNDTL } \\
200\end{array}$ & $\begin{array}{c}\text { (7) FNDTL } \\
100\end{array}$ & $\begin{array}{c}\text { (8) FNDTL } \\
50\end{array}$ & $\begin{array}{c}\text { (9) FNDTL } \\
30\end{array}$ \\
\hline \multicolumn{10}{|c|}{ Panel A: Annualized Cost-Adjusted Return } \\
\hline $1991-1999$ & $15.67 \%$ & $13.16 \%$ & $12.66 \%$ & $11.51 \%$ & $10.84 \%$ & $17.04 \%$ & $17.01 \%$ & $16.98 \%$ & $17.19 \%$ \\
\hline $2000-2008$ & $-2.69 \%$ & $-4.62 \%$ & $-6.10 \%$ & $-7.29 \%$ & $-8.95 \%$ & $-0.57 \%$ & $-0.69 \%$ & $-0.68 \%$ & $-0.70 \%$ \\
\hline $1991-2008$ & $6.10 \%$ & $3.89 \%$ & $2.86 \%$ & $1.68 \%$ & $0.46 \%$ & $7.88 \%$ & $7.80 \%$ & $7.79 \%$ & $7.87 \%$ \\
\hline \multicolumn{10}{|c|}{ Panel B: Annualized Standard Deviation } \\
\hline $1991-1999$ & $12.56 \%$ & $13.89 \%$ & $14.68 \%$ & $15.22 \%$ & $15.18 \%$ & $13.74 \%$ & $14.01 \%$ & $14.34 \%$ & $14.53 \%$ \\
\hline $2000-2008$ & $16.25 \%$ & $16.11 \%$ & $16.15 \%$ & $15.98 \%$ & $15.98 \%$ & $17.20 \%$ & $17.36 \%$ & $17.37 \%$ & $17.40 \%$ \\
\hline $1991-2008$ & $14.69 \%$ & $15.20 \%$ & $15.62 \%$ & $15.79 \%$ & $15.80 \%$ & $15.70 \%$ & $15.90 \%$ & $16.05 \%$ & $16.16 \%$ \\
\hline \multicolumn{10}{|c|}{ Panel C: Beta Coefficient } \\
\hline $1991-1999$ & 1.00 & 1.01 & 1.05 & 1.07 & 1.04 & 0.84 & 0.83 & 0.82 & 0.80 \\
\hline $2000-2008$ & 1.00 & 0.98 & 0.97 & 0.93 & 0.90 & 0.97 & 0.97 & 0.95 & 0.94 \\
\hline $1991-2008$ & 1.00 & 0.99 & 1.00 & 0.98 & 0.95 & 0.92 & 0.92 & 0.90 & 0.89 \\
\hline \multicolumn{10}{|c|}{ Panel D: Average Monthly Portfolio Turnover } \\
\hline $1991-1999$ & ------- & $2.54 \%$ & $2.40 \%$ & $2.61 \%$ & $2.82 \%$ & $6.25 \%$ & $5.98 \%$ & $5.82 \%$ & $5.60 \%$ \\
\hline $2000-2008$ & -------- & $1.72 \%$ & $1.83 \%$ & $2.04 \%$ & $2.26 \%$ & $6.34 \%$ & $6.22 \%$ & $6.04 \%$ & $5.81 \%$ \\
\hline $1991-2008$ & ------- & $2.13 \%$ & $2.11 \%$ & $2.32 \%$ & $2.54 \%$ & $6.29 \%$ & $6.10 \%$ & $5.93 \%$ & $5.70 \%$ \\
\hline
\end{tabular}

Source: Hsieh, Hodnett And Van Rensburg (2012: 110)

Table 3: Risk-Adjusted Performance Statistics Of Size Indexes

\begin{tabular}{|c|c|c|c|c|c|c|c|c|c|}
\hline Period & $\begin{array}{l}\text { (1) MSCI } \\
\text { World }\end{array}$ & $\begin{array}{c}\text { (2) CAP } \\
200\end{array}$ & $\begin{array}{c}\text { (3) CAP } \\
100\end{array}$ & $\begin{array}{c}\text { (4) CAP } \\
50\end{array}$ & $\begin{array}{c}\text { (5) CAP } \\
30\end{array}$ & $\begin{array}{c}\text { (6) FNDTL } \\
200\end{array}$ & $\begin{array}{c}\text { (7) FNDTL } \\
100\end{array}$ & $\begin{array}{c}\text { (8) FNDTL } \\
50\end{array}$ & $\begin{array}{c}\text { (9) FNDTL } \\
30\end{array}$ \\
\hline \multicolumn{10}{|c|}{ Panel A: Annualized Sharpe Ratio } \\
\hline $1991-1999$ & 0.872 & 0.607 & 0.540 & 0.446 & 0.402 & 0.896 & 0.877 & 0.854 & 0.857 \\
\hline $2000-2008$ & -0.354 & -0.477 & -0.567 & -0.648 & -0.752 & -0.211 & -0.216 & -0.216 & -0.216 \\
\hline $1991-2008$ & 0.150 & 0.000 & -0.066 & -0.140 & -0.217 & 0.254 & 0.245 & 0.242 & 0.246 \\
\hline \multicolumn{10}{|c|}{ Panel B: Annualized Treynor Ratio } \\
\hline $1991-1999$ & 0.109 & 0.083 & 0.076 & 0.064 & 0.059 & 0.147 & 0.147 & 0.149 & 0.156 \\
\hline $2000-2008$ & -0.058 & -0.078 & -0.095 & -0.112 & -0.134 & -0.037 & -0.038 & -0.039 & -0.040 \\
\hline $1991-2008$ & 0.022 & 0.000 & -0.010 & -0.023 & -0.036 & 0.044 & 0.043 & 0.043 & 0.045 \\
\hline \multicolumn{10}{|c|}{ Panel C: Annualized Jensen's Alpha } \\
\hline $1991-1999$ & 0.000 & $-2.50 \%$ & $-3.31 \%$ & $-4.57 \%$ & $-4.91 \%$ & $3.45 \%$ & $3.53 \%$ & $3.67 \%$ & $4.18 \%$ \\
\hline $2000-2008$ & 0.000 & $-2.07 \%$ & $-3.61 \%$ & $-5.04 \%$ & $-6.84 \%$ & $2.20 \%$ & $2.11 \%$ & $2.05 \%$ & $1.98 \%$ \\
\hline $1991-2008$ & 0.000 & $-2.12 \%$ & $-3.13 \%$ & $-4.24 \%$ & $-5.38 \%$ & $2.26 \%$ & $2.11 \%$ & $2.28 \%$ & $2.44 \%$ \\
\hline
\end{tabular}

Source: Hsieh, Hodnett And Van Rensburg (2012: 111)

The small firm effect in the global equity market is made evident by the negative relationship between the degree of portfolio concentration and the return on the cap-weighted indexes. The risk-adjusted returns measured by the Sharpe ratio, the Treynor ratio and Jensen's alpha reveal higher values for fundamental indexes against the MSCI market proxy throughout the examination period. Results for the same risk-adjusted measures for capweighted indexes are negative throughout the examination period.

Contrary to value indexes, which are based on capitalization and tend to underweight companies growing their fundamentals equally rapidly as their capitalization, fundamental indexes include reasonable weights of such companies in their portfolios (Hsu and Campollo, 2006). Despite critic of fundamental indexes still being growth biased, the effect of this growth bias, which should be a decrease in returns, is not evident. Instead higher excess returns are generated by these fundamental indexes.

\section{ARGUMENTS AGAINST FUNDAMENTAL INDEXATION AS A MEAN-VARIANCE EFFICIENT PROXY}

The evidence for fundamental indexation as a mean-variance efficient proxy reveals the benefits for the use of price-insensitive determinants of firm value. Authors, however, differ arguing against the mean-variance efficiency of fundamental indexes due to the belief that there exists a value bias within fundamental indexes causing the index to outperform the market capitalization weighted index. 


\section{Value Bias}

Mar et al. (2009) state that underlying the success of value strategies is the inability of the market to correctly estimate the future return potential of value stocks relative to growth stocks. Jun and Malkiel (2007) argue that the use of price insensitive measures of company size by fundamental indexes causes the index to systematically overweight value stocks and underweight growth stocks. The authors' arguments are consistent with that of Blitz and Swinkels (2008) who attribute the difference in market capitalization weights and fundamental weights to the difference in their ratio of fundamental value to market value. This weighing method ultimately causes the fundamental index to overweight value stocks and underweight growth stocks (Blitz et al. 2008). The assumed value bias inherent in the fundamental index argues against the index's mean-variance efficiency. This is due to the lack of outperformance achieved during periods in which the market correctly estimates the return potential of value stocks. In contrast to the arguments concerning the value bias inherent in fundamental indexes, Hsu and Campollo (2006) argue that fundamental indexes cannot simply be considered value indexes. The authors empirically prove that fundamental indexes outperform the market (S\&P 500) and a value index (Russell 1000) in bull markets as well as expansionary economic environments in which value indexes cannot outperform.

Arnott et al. (2005) confirm that a Fama-French three-factor regression reveals the exposure of fundamental indexes to the value factor. The exclusion of returns attributed to the value factor from the returns of the index leaves the fundamental index underperforming the market capitalization index (Arnott et al. 2005). The authors however go on to explain that the fundamental index does not seek to generate a positive portfolio alpha by engaging in active portfolio management (as assumed by the Fama-French three-factor model) as fundamental indexes are passive strategies.

\section{Active Portfolio Management}

Blitz et al. (2008) argues that fundamental indexes do not represent a classic passive strategy. The authors argue by identifying characteristics of fundamental indexes which, in their opinion, deviate from the characteristics of a passive strategy. These characteristics include: 1) the conflict of fundamental indexes with market equilibrium; 2) the index's failure to represent a buy-to-hold strategy and 3) the outperformance of the market capitalization index requiring subjective choices. Deviating from a passive strategy by means of the identified characteristics implies the active management of fundamental indexes, thus rejecting their mean-variance efficiency. These arguments are however in sharp contrast to the evidence presented by Dumont, de Chassart and Firer (2001) who argue that in an inefficient market; characterized by investor overreaction, only a market timing strategy along with a predictive accuracy allows for the active generation of portfolio alpha. The market timing strategies applied are of an active management nature as they require switching between asset classes to outperform the market (Ward and Terblanche, 2009).

\section{Rebalancing And Timing}

Fundamental indexes require rebalancing for the index to accurately reflect firm fundamentals and thus their respective weights within the index. Proponents of fundamental indexation rebalance the index per annum between the end of December and the beginning of January. Blitz, van der Grient and van Vliet (2010) argue that the outperformance of the fundamental index in a given year is attributed to the time at which the rebalancing takes place. The authors empirically prove that a fundamental index rebalanced per annum during March outperformed the market capitalization weighted index by more than $10 \%$, whereas a fundamental index rebalanced per annum during September, underperformed when compared to a market capitalization weighted index. To outperform the market on the basis of timing the index's rebalancing period violates an important characteristic of the fundamental index in two ways. Firstly, the fundamental index is labelled by its proponents as a passive strategy and the frequent rebalancing of the index with the aim to outperform the market, distorts the passivity of the index. Secondly, attempts to outperform the market with the use of varying rebalancing periods would require a predictive accuracy, again implying the active nature of such an index. The rationale for the rebalancing period as chosen by the proponents of fundamental indexation was to avoid the effects of tax on the firm's fundamentals. 


\section{CONCLUSION}

This paper provides a discussion of the fundamental index as a mean-variance efficient proxy for the market. This was done by contrasting price-sensitive market capitalization weighted indexes with fundamentally weighted indexes with the aim of determining which market proxy could be considered more mean-variance efficient, followed by evidence for and against this statement. Since the market-cap weighted index is only meanvariance efficient given the efficiency of the market, whilst the fundamental index incurs higher turnover; and may contain a value bias, its resistance to investor overreaction makes it a more valid mean-variance efficient proxy in an inefficient market.

\section{ACKNOWLEDGEMENTS}

We wish to thank the research office of the University of the Western Cape for their support. Additionally, we wish to thank Professor Heng-Hsing Hsieh for his valuable comments.

\section{AUTHOR INFORMATION}

Professor Kathleen Hodnett teaches and supervises postgraduate Finance Research and Statistics for Investments in the School of Business and Finance at the University of the Western Cape, South Africa. She obtained a PhD from the University of Cape Town with specializations in asset pricing models, alternative investments and artificial intelligence. She is an independent consultant for Financial Statistics. Email: Khodnett@uwc.ac.za

Gearé Botes, Khumbudzo Daswa, Kimberly Davids, Emmanuel Che Fongwa, and Candice Fortuin are postgraduate finance students in the School of Business and Finance at the University of the Western Cape, South Africa.

\section{REFERENCES}

1. Arnott R D, Hsu J and Moore P (2005). "Fundamental Indexation", Financial Analysts Journal, vol. 61, no 2, 83-99.

2. Blitz D and Swinkels L (2008). "Fundamental Indexation: An Active Value Strategy in Disguise", Journal of Asset Management, vol. 9, no 4, 42-49.

3. Blitz D, van der Grient B and van Vliet P (2010), "Fundamental Indexation: Rebalancing Assumptions and Performance", Journal of Index Investing, vol. 1, no 2.

4. De Bondt W F and Thaler R H (1985). "Does the Stock Market Overreact?" Journal of Finance, vol. 40, no 3, 793-805.

5. Dumont de Chassart M P and Firer C (2001). "Market Timing Under Different Market Conditions", Investment Analyst Journal, vol. 54, 19-32.

6. Fama, E.F. (1970). "Efficient Capital Markets: A Review of Theory and Empirical Work", Journal of Finance, vol. 25, 383-417.

7. FTSE (2012). FTSE Factsheet. Retrieved from FTSE: http://www.ftse.com/Indices/ FTSE_JSE_Africa_Index_Series/Downloads/FJRI.pdf

8. Hsieh H (2013). "Unlocking the Sects of Fundamental Indexes: Size Effect or Value Effect? Evidence from Emerging Stock Markets", Investment Management and Financial Innovations, vol. 10, no 4, 48-63.

9. Hsieh H, Hodnett, K, and Van Rensburg P (2012). "Fundamental Indexation: Does Firm Size Matter?" The Journal of Applied Business Research, vol. 28, no 1, 106-114.

10. Hsu J C (2006). "Cap-Weighted Portfolios are Sub-Optimal Portfolios”, Journal of Investment Management, vol. 4, no 3, 1-10

11. Hsu C and Campollo C (2006). "New Frontiers in Index Investing: An Examination of Fundamental Indexation", Journal of Indexes, 32-38.

12. Jun D and Malkiel B (2007). "New Paradigms in Stock Market Indexing", European Financial Management, vol. 14, no 1, 118-126.

13. Lintner J (1965). "The Valuation of Risk Assets and the Selection of Risky Investments in Stock Portfolios and Capital Budgets", Review of Economics and Statistics, vol. 47, no 1, 13-37. 
14. Mar J, Bird R, Casavecchia L and Yeung D (2009). "Fundamental Indexation: An Australian Investigation", Australian Journal of Management, vol. 34, no 1, 1-19.

15. Mossin J (1966). "Equilibrium in Capital Asset Markets", Econometrica, vol. 34, no 4, 768-783.

16. Markowitz H (1952). "Portfolio Selection", Journal of Finance, vol.7, no 1, 77-91.

17. Paglia J (2001). Has the Dow Really Escaped the Bear? Retrieved from Pepperdine: http://gbr.pepperdine.edu/2010/08/has-the-dow-really-escaped-the-bear/

18. Sharpe W (1965). "Risk-Aversion in the Stock Market: Some Empirical Evidence", Journal of Finance, vol. 19 , no 3, 416-422.

19. Siegel, J. (2006, June 14). The 'Noisy Market' Hypothesis. Retrieved from The Wall Street Journal Online: http://online.wsj.com/article_print/SB115025119289879729.html

20. Stotz O, Wanzenried G and Döhnert K (2010). "Do Fundamental Indexes Produce Higher Risk-Adjusted Returns than Market Cap Indexes? Financial Markets and Portfolio Management, vol. 24 (3), 220-223.

21. Tobin J (1958). "Liquidity as Behaviour toward Risk", The Review of Economic Studies, vol. 25, 65-

22. Walkshäusl C and Lobe S (2009). Fundamental Indexing Around the World", University of Regensburg.

23. Ward M and Terblanche RC (2009). "Market Timing on the JSE using Exchange Rate Fluctuations", Investment Analysts Journal, no 70, 1-10

24. Yahoo. (2001, March). DJI Historical Prices. Retrieved from Yahoo Finance: http://finance.yahoo.com/q/hp? $\mathrm{s}={ }^{\wedge} \mathrm{DJI}+$ Historical+Prices 


\section{NOTES}

